\title{
Design Comparisons for Procurement Systems
}

\author{
Charles J. Thomas* \\ and
}

Bart J. Wilson ${ }^{\dagger}$

We use experimental techniques to compare first-price auctions to a common but previously unexamined exchange process that we term "multilateral negotiations." Initially, we find that transaction prices are statistically indistinguishable in the two institutions with four sellers, but that prices are higher in multilateral negotiations than in first-price auctions with two sellers. Surprisingly, we find in two-seller environments that a history of multilateral negotiations leads to higher auction prices, which suggests that buyers may see little price effect by moving from negotiations to auctions.

Additional Key Words and Phrases: auctions, bargaining, negotiation, experimental economics

\section{INTRODUCTION}

Designing an exchange institution is potentially one of the most important decisions made by a procurement manager. The design influences the speed and ease with which the transaction is consummated, the number of participating suppliers, their price-setting strategies, and ultimately the price the buyer pays. Making an informed design choice requires understanding how designs affect outcomes. The rapid growth of B2B exchanges makes this choice even more important; rivals' use of successful procurement strategies can be very costly to laggard firms.

Because the implementation of any new market mechanism involves a number of choices, we believe that the laboratory method of experimental economics can help address a growing host of Internet market design questions. With an informed experimental design, controlled laboratory experimentation can accelerate the process of designing attractive and effective institutions for the Internet. As e-commerce becomes a central business element, it is essential to understand human behavior in strategic Internet environments. Field studies, while a useful and necessary part of research, are limited by the lack of complete information about the participants and a lack of environmental controls (demand changes, cost changes, and a plethora of other unknown and unobservable factors). Experimental economics bridges this gap, by yielding complete

Address:

* Federal Trade Commission, 600 Pennsylvania Ave., NW, Washington, D.C. 20580, USA

${ }^{\dagger}$ Economic Science Laboratory, University of Arizona, McClelland 116, Tucson, AZ 85721, USA

Permission to make digital or hard copies of part or all of this work for personal or classroom use is granted without fee provided that copies are not made or distributed for profit or direct commercial advantage and that copies show this notice on the first page or initial screen of a display along with the full citation. Copyrights for components of this work owned by others than ACM must be honored. Abstracting with credit is permitted. To copy otherwise, to republish, to post on servers, to redistribute to lists, or to use any component of this work in other works, requires prior specific permission and/or a fee. Permissions may be requested from Publications Dept, ACM Inc., 1515 Broadway, New York, NY 10036 USA, fax +1 (212) 869-0481, or permissions@acm.org. 
information to researchers and allowing them to observe how behavior develops from controlled fundamentals. Here we report both new and existing results (see [9]) to illustrate how experiments can enhance our understanding of human behavior in two electronic exchange mechanisms. The first is the first-price sealed-bid auction, in which sellers simultaneously offer prices to a buyer, and the low price seller is awarded the contract at the price it offered. Auctions are used extensively in industrial procurement and online transactions, and have been used to allocate products as varied as radio spectra, electric power, pollution rights, government securities, and mineral rights (see [5], [10], [1], [6], and [4]).

The second mechanism is the multilateral negotiation, in which a buyer accepts initial offers and then negotiates discounts by playing the sellers off one another. This mechanism is pervasive in industrial procurement and in transactions such as the securing of job offers and the purchasing of computers, contractors' services, and automobiles. Though multilateral negotiations have not yet been formally modeled in the economics literature, they are used in practice: negotiation-based software agents have been developed to handle online procurement. For example, [8] implements a server for automated, Web-based negotiations between buyers and sellers. Regrettably, researchers and practitioners in computer science and management information systems who are creating both artificially intelligent and direct human mechanisms for multilateral negotiations have little economic research to guide their work. We take a first step in that direction by comparing multilateral negotiation markets to first-price auctions.

\section{EXPERIMENTAL DESIGN AND PROCEDURES}

In the absence of a tractable multilateral negotiation model, we conducted a heuristic experiment (see [7]) to compare first-price auctions and multilateral negotiations.

Using " $F$ " to denote a sequence of first-price auctions and " $N$ " to denote a sequence of multilateral negotiations, we pair one treatment with sequences $N F F N$ to one with sequences $F F N F$. The first and third sequences consist of 12 transactions, the second consists of 16 , and the fourth consists of 6 . We vary the treatments by setting the number of sellers at two and four per buyer, respectively.

For each of the four treatments, $\{2$ sellers, 4 sellers $\} \times\{N F F N, F F N F\}$, we have four groups of subjects. Each subject is assigned a specific role (buyer or seller) in a specific group for the duration of the session. A seller's cost characteristics consist of 46 random draws from the Uniform distribution on $[0,6.00]$. Of the eight groups with four sellers, seller $i(i=1,2,3,4)$ has the same cost draws across groups. Of the eight groups with two sellers, seller $i(i=1,2)$ has the same cost draws across groups. Moreover, the costs of sellers 1 and 2 in the two-seller treatment are the same as the costs of sellers 1 and 2 in the four-seller treatment. The control afforded by matching sellers' costs is a key feature of experimental methods.

Our experiment consisted of 736 first-price auctions or multilateral negotiations using sixty-four undergraduate student volunteers. Sellers earned cash by selling units of a fictitious commodity at prices above the costs that we gave them, and buyers earned cash by purchasing units below an induced value (which can be thought of as a resale value to the experimenter).

The instructions for the first-price auctions are based on those used by [2] and [3]. The instructions for the multilateral negotiations are newly developed. All play and intraplayer communications took place on the computer network at the Economic Science Laboratory, using software developed there. 
Publicly read instructions made common knowledge that the sellers' costs were assigned randomly and independently each period from the Uniform distribution on $[0,6.00]$, and that the buyer's value was 6.00 .

The random cost draw for a given period was disclosed to the subject at the beginning of the period. In a first-price auction, after learning his cost each seller had four minutes to submit his offer, though in practice this limit was never binding. The computer awarded the item to the seller that submitted the lowest offer once all offers had been submitted, provided the lowest offer was less than 6.00. At the end of the auction, the market price was announced electronically to all market participants, after which the session proceeded to the next period. The winning seller with $\cos t c$ earned $p-c$, where $p$ denotes the market price. The buyer earned $6.00-p$.

In a multilateral negotiation, after learning his cost each seller had 30 seconds in the first phase of the period to submit his initial offer. The instructions indicated that the seller would be able to lower his offer at any time in the second phase of the period. Once the buyer received all initial offers, the clock was reset to four minutes for the negotiation phase. At any time in the negotiation phase, a seller could (only) lower his offer, and the buyer could accept a single seller's offer. Furthermore, a buyer and a seller could engage in nonbinding discussions concerning a deal. The sellers could only communicate with their buyer. However, the buyer could negotiate individually with any seller, but only one at a time, while retaining standing offers from the other sellers. This process is meant to parallel the naturally occurring process of a buyer formally soliciting RFPs and then negotiating in person, over the phone, or through an online exchange until a transaction price is agreed upon. The subjects only knew the identification numbers of the parties with whom they communicated, and the sellers had no verifiable information about the initial or subsequent offers made by other sellers. Once the buyer accepted an offer, the market price was announced electronically to all market participants, after which the session proceeded to the next period. The subjects' payoff functions are the same as in the auction setting.

It was public information that the same sellers were matched with the same buyer for the duration of the experiment, but the prices, efficiency levels, and negotiation transcripts revealed no evidence of collusion.

Participants received $\$ 5$ for showing up on time, plus their salient earnings. With the intent of equalizing all subjects' ex ante payoffs, the exchange rates were imputed from the US\$ payoffs in the first-price auction experiments reported in [2]. In the four-seller sessions, the buyers' exchange rate was US\$1 for 8 experimental dollars, and the sellers' exchange rate was US $\$ 1$ for 0.25 experimental dollars. In the two-seller sessions, the exchange amounts were 6 and 2 experimental dollars for each US\$1, respectively. The average subject earned $\$ 16.75$ plus $\$ 5$ for showing up on time.

\section{EXPERIMENTAL RESULTS}

For each period, our data include the institution used, the transaction price, each seller's cost, and each seller's initial and subsequent offers in the negotiations. We analyze the data using a linear mixed-effects model for repeated measures. The dependent variable is the observed market price. The treatment effects (Two Sellers vs. Four Sellers and Negotiation vs. First-price Auction) and an interaction effect are modeled as (zero-one) fixed effects, while the 16 independent sessions are modeled as random effects, $e_{i}$. Specifically, we estimate the model: 
Table 1. Average transaction and predicted Nash* prices by regime

\begin{tabular}{lcccc}
\multicolumn{1}{c}{ Sequence } & \multicolumn{2}{c}{$\begin{array}{c}\text { Two Sellers } \\
\text { Nash }\end{array}$} & \multicolumn{2}{c}{ Four Sellers } \\
FFNF & Ave. & $\begin{array}{c}\text { Nash } \\
\text { Prediction }\end{array}$ & Ave. & Prediction \\
Periods 1-12: $F$ & 3.10 & 4.12 & 1.87 & 2.49 \\
Periods 13-28: $F$ & 3.01 & 4.01 & 2.01 & 2.79 \\
Periods 29-40: $N$ & 3.22 & 4.11 & 1.69 & 2.43 \\
Periods 41-46: $F$ & 3.01 & 4.07 & 1.60 & 2.31 \\
& & & & \\
NFFN & & & & \\
Periods 1-12: $N$ & 3.69 & 4.12 & 1.88 & 2.49 \\
Periods 13-28: $F$ & 4.01 & 4.01 & 2.12 & 2.79 \\
Periods 29-40: $F$ & 4.07 & 4.11 & 1.74 & 2.43 \\
Periods 41-46: $N$ & 3.52 & 4.07 & 1.54 & 2.31
\end{tabular}

*The predicted Nash prices are conditional on the draws and the assumption of risk-neutral price-setting. The ex ante Nash predictions are a price of 4.00 with two sellers and 2.40 with four sellers.

$$
\text { Price }_{i j}=\mu+e_{i}+\beta_{1} \text { TwoSellers }_{i}+\beta_{2} \text { Negotiation }_{i}+\beta_{3} \text { TwoSeller }_{i} \times \text { Negotiation }_{i}+\varepsilon_{i j},
$$

where $i$ indexes the sessions and $j$ the periods (e.g., $j=1,2, \ldots, 12$, for the first regime of 12 periods). The price effect of moving from a four-seller auction to a four-seller negotiation is given by $\beta_{2}$, and from a two-seller auction to a two-seller negotiation is $\beta_{2}$ $+\beta_{3}$. Our hypothesis tests of whether these expressions differ from zero typically are two-sided, and we denote one-sided tests by a " $\uparrow$ " next to the listed $p$-value. We allow heteroskedastic errors by session when estimating the model via restricted maximum likelihood. For brevity's sake, the results are not reported here (see [9] for a complete description).

Our primary finding compares the transaction prices in the initial institutional regime.

Finding 1: In the initial institutional regime, transaction prices are statistically indistinguishable in first-price auctions and multilateral negotiations with four sellers. However, multilateral negotiation prices are higher than first-price auction prices with two sellers.

Evidence: Figure 1 displays by treatment the prices for the first 12 periods, while Table 1 reports the average prices over the sequence. The price patterns in the four-seller treatments are quite similar, while the price patterns in the two-seller treatments are very different.

With four sellers, the estimated Negotiation effect is nearly zero and is highly insignificant $\left(\hat{\beta_{2}}=-0.004, p\right.$-value $=0.9856$ ), which is consistent with our visual examination of the four-seller transaction prices in Table 1 and Figure 1. However, with two sellers the negotiations significantly raise transaction prices by 0.880 experimental dollars $(29.5 \%)$ above the level in first-price auctions $(p$-value $=0.0038)$. 

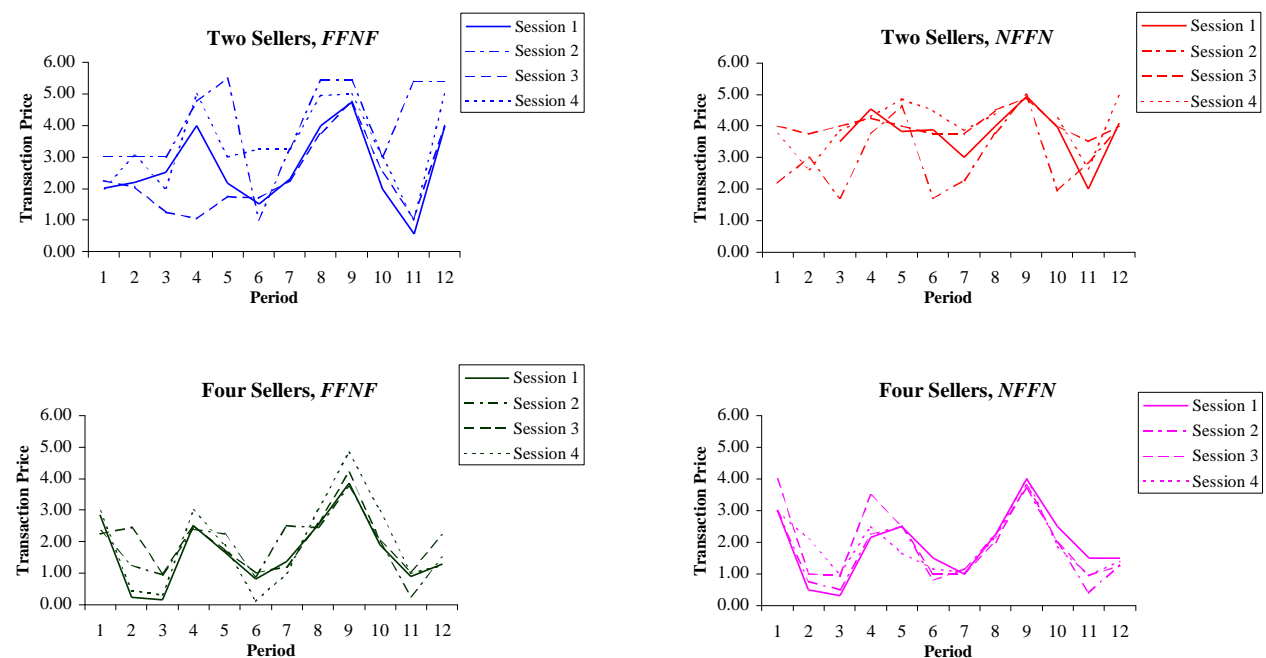

Figure 1. Average transaction and predicted Nash prices by regime

Figure 2 provides additional insight into the observed price differences in the twoseller treatment. This figure depicts the difference between the minimum cost and the average transaction price for the two-seller data in Figure 1. The minimum cost is also plotted in Figure 2. When the minimum cost is relatively low, the negotiations have consistently higher markups over cost. However, when the minimum cost is high, the markups are similar and low. The two institutions differ in that the one-shot nature of the auction leads to more competitive offers by the sellers, but the real-time nature of multilateral negotiations grants the low cost seller the ability to start high and drop his price only as far as necessary to convince the buyer to complete the sale. This occurs sooner when both sellers' costs are high, so the markups are similar across the $N$ and $F$ sequences. It is notable that this effect with two sellers goes away when four sellers are competing for the buyer's business.

Our second finding illustrates how a history of trading with different institutions affects prices. As procurement moves onto the Internet, agents that adopt new institutions will have prior experience with others. For example, firms that employ

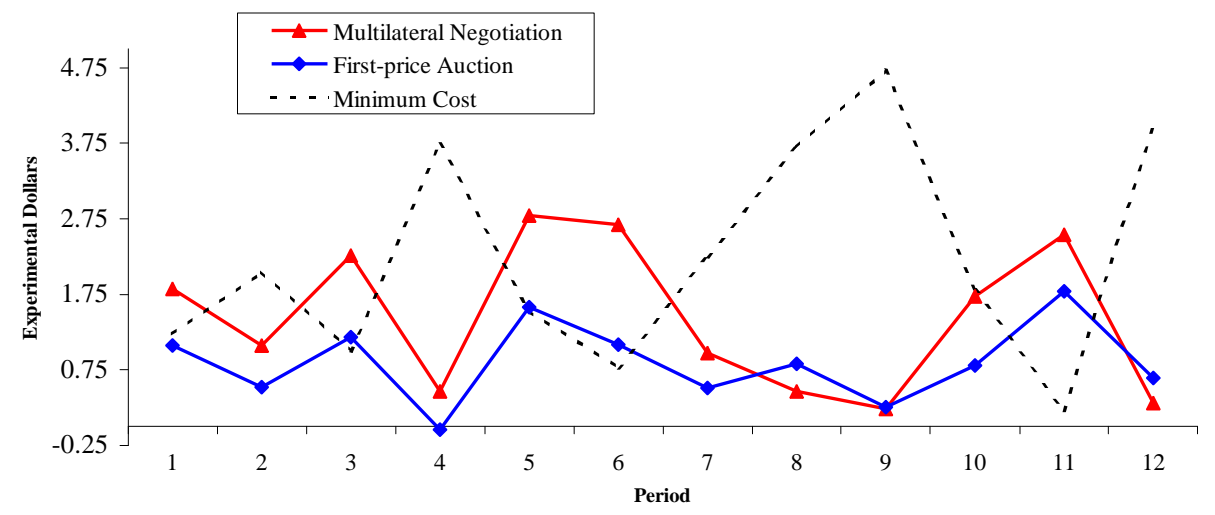

Figure 2. Differences between Transaction Prices and Minimum Cost with Two Sellers 
negotiations in traditional procurement settings may move to online auctions. Hence, the impact of institutional experience on future outcomes is a relevant issue. The first part of the finding compares the common 16 first-price auctions in periods 13 through 28, and the second compares the behavior in periods 29 through 40 .

Finding 2a: With two sellers, sellers in first-price auctions who only have prior experience with multilateral negotiations transact at higher prices than sellers who only have prior experience with first-price auctions. With four sellers, there is no difference in transaction prices.

Evidence: Here we test whether a history of negotiation has a permanent effect such that first-price auction prices are higher in the NFFN sessions. The average prices over the sequence reported in Table 1 support this finding. With two sellers, negotiations significantly raise transaction prices by 1.073 experimental dollars above the level in first-price auctions $\left(p\right.$-value $\left.=0.0002^{\dagger}\right)$. However, we find no difference in transaction prices with four sellers $\left(\hat{\beta_{2}}=0.108, p\right.$-value $\left.=0.6513\right)$.

Finding 2b: With two sellers, sellers in first-price auctions who have prior experience with multilateral negotiations and first-price auctions transact at higher prices than do sellers in multilateral negotiations who only have prior experience with first-price auctions. With four sellers, there is no difference in transaction prices.

Evidence: Here we test whether the effect of a history of negotiations in the NFFN sessions offsets the treatment effect of the multilateral negotiations in the FFNF sessions. The data reported in Table 1 support this finding. With two sellers, the history of negotiation significantly raises auction prices by 0.801 experimental dollars above their level in multilateral negotiations $(p$-value $=0.0139)$. However, we find no difference in transaction prices with four sellers $\left(\hat{\beta_{2}}=-0.068, p\right.$-value $\left.=0.8205\right)$.

Finding 2 indicates that the order in which our subjects are exposed to the two institutions has a lingering effect on transaction prices. With two sellers, initial exposure to multilateral negotiations leads to higher prices throughout the session than initial exposure to first-price auctions. One explanation for this result is that the competition induced by the one binding offer of the first-price auction overwhelms the opportunity for the sellers later to keep prices higher with multilateral negotiations. Another explanation is that the nature of competition in the initial institution permanently affects how sellers formulate their bidding and negotiating strategies.

\section{CONCLUSION}

We use experimental techniques to compare first-price auctions to a common but previously unexamined exchange process that we term "multilateral negotiations." In this process, a buyer solicits price offers for a homogeneous product from sellers with heterogeneous costs, and then plays the sellers off one another to obtain additional price concessions. This process is observed in industrial procurement, haggling over new car prices, and wage negotiations, to name but a few examples.

Our findings have implications for the design of procurement systems. First, in the initial regime the equivalence of the institutions depends on the number of sellers. With two sellers, transaction prices are higher in multilateral negotiations than in first-price 
auctions. With four sellers, transaction prices are statistically indistinguishable across the institutions. These results suggest that concerns about the exchange mechanism are important with a small number of suppliers.

Second, initial exposure to multilateral negotiations with two sellers leads to a permanently higher path for transaction prices in all institutions than does initial exposure to first-price auctions. With four sellers, there is virtually no across-institution difference in the price paths. Hence, if a buyer and his suppliers traditionally have engaged in multilateral negotiations, then moving to online auctions may not reduce prices.

Our results are intriguing, but they would benefit from further research. First, it would be useful to analyze settings with different numbers of sellers. At this point, we do not fully know the price-concentration relationship between the institutions. Second, it would be useful to analyze settings with differences in the cost distributions across sellers, to account for asymmetries across suppliers. To date, this issue has not been explored experimentally with auctions, much less with multilateral negotiations. Finally, it would be interesting to let the sellers elect whether to expend the costs necessary to enter the procurement contest, based on the exchange mechanism selected by the buyer. As these examples illustrate, our initial experiment suggests a wide range of interesting research possibilities for the laboratory and the field.

\section{ACKNOWLEDGEMENTS}

We thank the Economic Science Laboratory at the University of Arizona for providing financial support, and Todd Swarthout for skillfully writing the software. The views expressed in this paper are those of the authors and do not necessarily represent the views of the Federal Trade Commission or any individual Commissioner.

\section{REFERENCES}

[1] Cason, T., "An Experimental Investigation of the Seller Incentives in the EPA's Emission Trading Auction," American Economic Review, 85, 905-922 (1995).

[2] Cox, J., B. Roberson, and V. Smith, "Theory and Behavior of Single Object Auctions," in Research in Experimental Economics, Vol. 2, General Editor, V. Smith, JAI Press, Greenwich (1982).

[3] Cox, J., V. Smith, and J. Walker, "Theory and Individual Behavior of First-Price Auctions," Journal of Risk and Uncertainty, 1(1), 61-99 (1988).

[4] McAfee, R.P. and J. McMillan, "Auctions and Bidding," Journal of Economic Literature, 25, 699-738 (1987).

[5] McAfee, R.P. and J. McMillan, "Analyzing the Airwaves Auction," Journal of Economic Perspectives, 10, 159-175 (1996).

[6] Milgrom, P. and R. Weber, "A Theory of Auctions and Competitive Bidding," Econometrica, 50, 1089-1122 (1982).

[7] Smith, V., "Microeconomics as an Experimental Science," American Economic Review, 72, 923-955 (1982).

[8] Su, S., C. Huang, and J. Hammer, "A Replicable Web-Based Negotiation Server for E-Commerce," Proceedings of the $33^{\text {rd }}$ Hawaii International Conference on System Sciences (2000).

[9] Thomas, C. J. and B. J. Wilson, "A Comparison of Auctions and Multilateral Negotiations," FTC Working Paper \#231, 2000. Available at http://fs.econlab.arizona.edu/ bwilson/working_papers.htm.

[10] Wolfram, C., "Strategic Bidding in a Multiunit Auction: An Empirical Analysis of Bids to Supply Electricity in England and Wales," RAND Journal of Economics, 29, 703-725 (1998). 